RESENHA TEMA LIVRE

\title{
Debatendo o pensamento social de Carlos Nelson Coutinho
}

\section{Bruno Bruziguessi}

Universidade Federal de Juiz de Fora (UFJF)

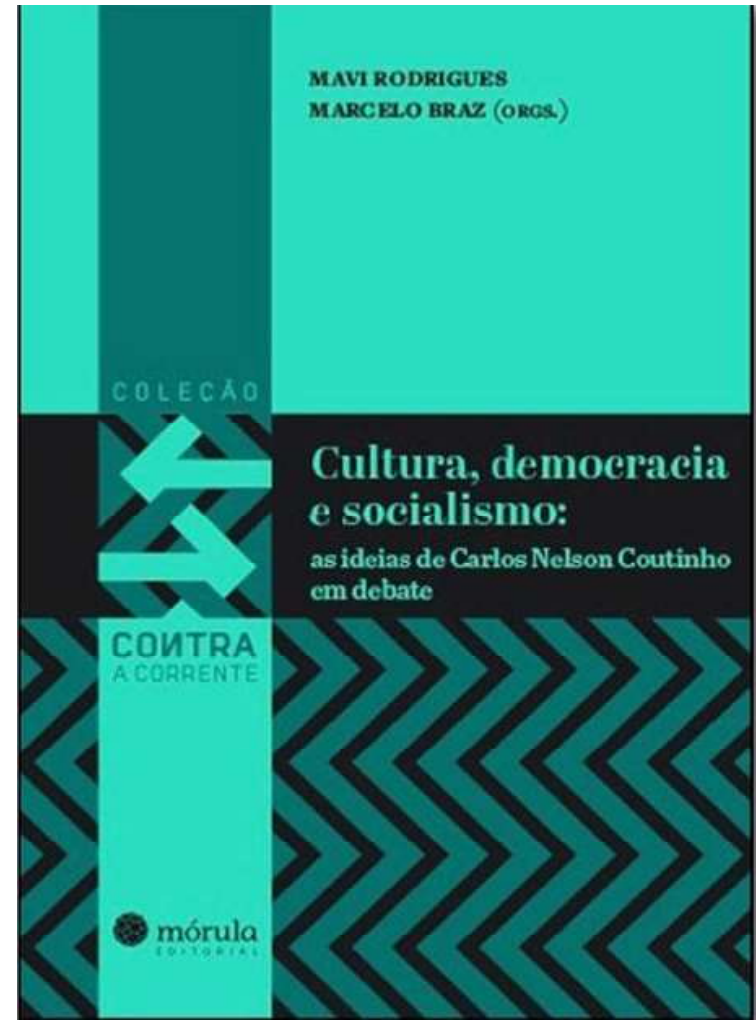

\section{RESENHA: Debatendo o pensamento social de Carlos Nelson Coutinho}

BRAZ, Marcelo; RODRIGUES, Mavi (Org.). Cultura, democracia e socialismo: as idéias de Carlos Nelson Coutinho em debate. Rio de Janeiro: Mórula, 2016. 248 p.

\section{REVIEW: Debating the Social Thinking of Carlos Nelson Coutinho}

BRAZ, Marcelo; RODRIGUES, Mavi (Org.). Cultura, democracia e socialismo: as idéias de Carlos Nelson Coutinho em debate. [Culture, democracy and socialism: The ideas of Carlos Nelson Coutinho in debate]. Rio de Janeiro: Mórula, 2016. 248 p. 
No dia 20 de setembro de 2012, tanto a esquerda quanto a academia brasileira perderam um de seus mais proeminentes intelectuais, Carlos Nelson Coutinho, que, desde a década de 1960, vinha contribuindo de forma decisiva para a renovação do marxismo, ampliando o escopo categorial com fidedignidade ao método, colaborando de forma decisiva nas formulações de uma gama de áreas de discussão, enriquecendo de forma definitiva o pensamento social crítico no Brasil. Quando um intelectual dessa grandeza falece, é normal uma movimentação mais intensa no sentido de retomar toda a amplitude de seu pensamento, suas análises e interpretações - não que isso já não ocorresse antes, mas ganha outras proporções de agora em diante - tanto em um esforço de homenageálo, de estabelecer balizamentos teórico-políticos e atualizações de suas formulações, quanto de estabelecer uma crítica e mesmo contraposição a essas formulações e a seu posicionamento político.

Desta forma, o livro Cultura, democracia e socialismo: as idéias de Carlos Nelson Coutinho em debate, organizado por Marcelo Braz e Mavi Rodrigues - resultado de intervenções no Seminário Internacional Carlos Nelson Coutinho e a Renovação do Marxismo, realizado de 11 a 13 de novembro de 2013, no Campus da Praia Vermelha, da Universidade Federal do Rio de Janeiro - propõe exatamente o que seu subtítulo aponta: debater as idéias materializadas em um rico arsenal teórico-interpretativo daquele que, talvez, tenha se tornado um dos principais e mais sofisticados pensadores sociais brasileiros da contemporaneidade.

O livro se divide em duas partes, sendo a primeira, denominada "Marxismo, socialismo e democracia", dedicada ao debate teórico, mesmo filosófico, que expressa o processo de apropriação de Coutinho das categorias da tradição marxista e, ao mesmo tempo - de forma dialética, como é característico em suas formulações - exprimindo o movimento de renovação dessa tradição frente a uma conjuntura social, cultural e política em constante mudança, sobretudo os dilemas da construção do socialismo.

\section{Desta forma, o livro [...]}

\section{propõe exatamente o que seu}

subtítulo aponta: debater as

idéias materializadas em um

rico arsenal teórico-

interpretativo daquele que,

talvez, tenha se tornado um dos

principais e mais sofisticados

pensadores sociais brasileiros

da contemporaneidade.

Dessa primeira parte, trataremos, inicialmente, dos textos de Guido Liguori, Francisco Louçã e Michael Lowy, que abordam, dentro do pensamento de Coutinho, o debate da democracia, sua relação com o socialismo e o sentido de valor universal tratado inicialmente em polêmico ensaio de 1979 - "A democracia como valor universal" - e que permeará o conjunto das obras do pensador baiano, sobretudo em suas elaborações, que podemos chamar de maduras. Liguori e Louçã caminham em perspectivas diferentes. O primeiro destaca três questões centrais que foram extraídas, a partir da apropriação da obra de Gramsci e do socialismo italiano, e que se tornaram centrais nas concepções teórico-políticas de Coutinho: o próprio debate da democracia; o antidogmatismo em relação ao marxismo stalinista; e, por fim, a centralidade da política. Liguori dá ênfase ao movimento de renovação realizado pelo marxismo de Coutinho, uma "renovação dialética permanente" (p. 37), colocando a questão da democracia como o caminho para o socialismo. Louçã, entretanto, é crítico à concepção de democracia desenvolvida por Coutinho, influenciada pelo eurocomunismo que, para o autor português, seria um paradoxo: ao tempo em que aponta a superação do capitalismo, aponta para o fim do antagonismo entre comunismo e social-democracia, assim como o conceito de reformismo revolucionário que, para o autor, representa, ao mesmo tempo, o meio e o fim a que se quer alcançar, sendo "uma coisa estranha" (p. 44). Já o texto de Michael Lowy, ao definir a referência de Gramsci na obra de Coutinho, sobretudo através da conquista da hegemonia pelo consenso, aponta que há uma inspiração de Rosa Luxemburgo em sua formulação, especialmente em relação à defesa de uma democracia socialista que, para Lowy, é o ponto central da elaboração. Parte dessa inspiração pode ser percebida nas críticas que Coutinho fez à Internacional Comunista, ao bolchevismo, ao dogmatismo stalinista e, consequentemente, ao Partido Comunista Brasileiro (PCB).

Se esses três primeiros autores argumentaram a partir da influência gramsciana de Carlos Nelson Coutinho, os próximos três autores da primeira parte - Antonino Infranca, José Paulo Netto e Mavi Rodrigues - farão reflexões a partir do período de maior influência lukacsiana do pensador. O primeiro deles, o italiano Infranca, destaca o uso crítico das concepções do filósofo húngaro, como "intimismo a sombra do poder" (p. 56), "realismo crítico" (p. 57) e, sobretudo, de "via prussiana" (p. 54), como se Coutinho quisesse tratá-las como alegoria, sem fazer um uso mecânico dos conteúdos históricos-sociais, tanto do contexto de origem da formulação dos conceitos, quanto do contexto em análise, transformando este conceito em categoria para análise da 
realidade brasileira. Infranca finaliza sua reflexão ao tratar da relação que Coutinho estabelece entre Lukács e Gramsci, apontando uma aproximação política maior com Gramsci, mesmo enxergando a influência de Lukács em toda a sua obra. Os textos de Netto e Rodrigues retomam o período que Coutinho chamou de "longos anos 1960" (p. 121), que se inicia com o XX Congresso do Partido Comunista da URSS (PCUS), em 1956 - quando foi revelado ao mundo os crimes políticos cometidos pelo governo soviético, comandado por Stalin - passando pelas revoltas estudantis de 1968, na França, e culminando, na segunda metade dos anos de 1970, com o advento do eurocomunismo. Os autores demarcam este como o período de formação intelectual de Coutinho, com especial influência de Lukács em suas primeiras elaborações, destacando o contexto de emersão da renovação do marxismo, enquanto ruptura com a chamada "ideologia oficial" (p. 122) engessada pelo período stalinista, abrindo possibilidade para a retomada das obras originais de Marx, como também a incorporação de novas reflexões do campo crítico e a reflexão de novas questões postas pelo capitalismo contemporâneo. É nessa efervescência que Coutinho constrói a crítica ao estruturalismo, sob a luz desse processo de renovação do marxismo, enquanto perspectiva teórica que passa a se enraizar nas universades, com a publicação do livro "O estruturalismo e a miséria da razão", em 1972, que servirá também de crítica às bases para o que passou a ser conhecido, na contemporaneidade, como pensamento pós-moderno. Mais tarde, com a aproximação às elaborações de Gramsci, também como resultado da construção teórica e política da renovação do marxismo, passa a debater a articulação entre democracia e socialismo, com influência do eurocomunismo.

A segunda parte do livro, intitulada "Luta política e luta ideológica no Brasil", é composta por artigos que tratam das contribuições de Coutinho para a análise da realidade brasileira, desde reflexões acerca da formação social, até análises de momentos conjunturais da história do país, como a redemocratização. Também traz reflexões sobre os dilemas da esquerda e do movimento socialista, e sobre o debate da cultura e da educação no Brasil.

O primeiro texto dessa segunda parte é de Antonio Carlos Mazzeo, que aponta o que seriam, em sua perspectiva, três contradições nas formulações de Coutinho acerca da "particularidade histórica" (p. 140-141) da sociedade brasileira, polemizando acerca das características, sobretudo, da base colonial escravista como "aspecto definidor" (p. 151) de um desenvolvimento não-clássico do capitalismo no Brasil. Essas três contradições, que são desenvolvidas ao longo do texto de Mazzeo, referem-se:

[...] a) a definição de que na colônia se produz 'valores de uso' que transformam-se em valores de troca no mercado; b) a concordância 'aproximativa' com a noção de 'modo de produção escravista' e a definição imprecisa que confere [...] o caráter da colonização e da articulação da formação social brasileira com o mercado mundial [...]; e c) a especificidade do 'prussianismo' brasileiro. (p. 144).

Um aspecto que foi recorrente em alguns textos do livro foi a relação de Coutinho com o PCB, ou melhor, com a política do PCB no período de uma suposta tentativa de renovação da organização após a divulgação do Relatório Kruchev no XX Congresso do PCUS, em 1956. Desta forma, os textos de Marcelo Braz e Marcos Del Roio exploram o contexto de formação do marxismo de Coutinho à luz desse processo, que é um desdobramento particular de uma nova dinâmica posta ao movimento comunista em âmbito global. O texto de Braz aborda o período de crise e tentativa de renovação do direcionamento dessa organização; no mesmo momento em que Coutinho foi, por um lado, um produto desse processo, ao incorporar os aspectos de um marxismo em renovação - e, porque não, em abertura - e, por outro, sujeito das mudanças do PCB, sobretudo no debate cultural. Já Del Roio analisa o debate em torno da democracia no Brasil de Coutinho, em escritos de 1977 e 1979, momento de crítica à ditadura e de composição de uma proposta democrática unitária para as forças anti-regime, onde faz apontamentos fortemente inspirados no pensamento político de Gramsci e no eurocomunismo, colocando o debate democrático no cerne do socialismo.

Ainda sobre o tema da democracia no Brasil, um dos mais debatidos e controversos da obra de Coutinho, os textos de Mauro Iasi e Milton Temer fazem abordagens praticamente opostas. Iasi afirma que, no pensamento de Coutinho, o processo de democratização da sociedade brasileira levaria ao fim do prussianismo, e que o fortalecimento da sociedade civil, necessariamente, fortaleceria a luta dos trabalhadores. Paradoxal e concretamente, a formação de uma sociedade civil não teria levado a nenhum favorecimento à luta pelo socialismo; além disso levar a uma tendência gradualista de conquista do Estado no pensamento de Coutinho, onde seria possível, a partir da socialização da política, o controle deste pelas massas trabalhadoras e a ruptura revolucionária. Iasi parece apontar uma sobrepolitização, ou mesmo um politicismo, no pensamento de Coutinho, uma responsabilidade excessiva no processo de socialização da política, que pode levar a uma perda da perspectiva de classe na análise do Estado. Já Temer dá uma ênfase maior no debate eleitoral, apontando essa via de luta como possibilidade de mudanças qualitativas da realidade brasileira, ou seja, a mudança das condições 
de luta dos trabalhadores, o verdadeiro sentido do processo de socialização da política; daí a importância em retomar uma importante máxima de Coutinho, a de associar a luta institucional, parlamentar, com a luta de massas, dos movimentos sociais, sem uma negação por princípio de qualquer forma de enfrentamento.

O texto que encerra o livro é de autoria de Lucia Neves, que traz uma síntese teórica das contribuições da obra de Coutinho, sobretudo do uso dado por ele às categorias gramscianas e ao debate da democracia no Brasil, que alicerçam o Coletivo de Estudos de Política Educacional. Tendo como norte de referencial os estudos acerca da ocidentalização da sociedade brasileira sob a égide de uma hegemonia burguesa, fundamentada na política educacional e cultural do Brasil, o neoliberalismo. É exatamente nesse contexto que Neves cunhou a categoria de uma nova pedagogia da hegemonia para explicitar uma pedagogia, um projeto político-cultural, forjada pelo projeto neoliberal no Brasil a partir dos anos de 1990.

Esse ótimo livro, muito mais em um sentido de colocar em polêmica aberta as concepções teóricas e políticas de Carlos Nelson Coutinho, é uma forma de manter viva não só a memória, mas, sobretudo, mostrar a atualidade e a força das idéias desse pensador e instigar ainda mais o processo de estudo do conjunto de sua obra, tanto pela vastidão de temáticas e referências clássicas que usava, quanto pelas polêmicas que sempre levantou, tendo no seu pensamento uma importante arma de crítica ao conservadorismo que avança - seja pelo reacionarismo ou pela pós-modernidade - enquanto crítico permanente das posições da esquerda brasileira e seu processo de compreender o Brasil, desde sua formação sócio-histórica até a contemporaneidade.

\section{Bruno Bruziguessi}

brunobruziguessi@yahoo.com.br

Mestre em Serviço Social pela Universidade Federal de Juiz de Fora (UFJF)

Professor da Faculdade de Serviço Social da Universidade Federal de Juiz de Fora (UFJF)

\section{UFJF}

Rua José Lourenço Kelmer, s/n, Martelos

Juiz de Fora - Minas Gerais - Brasil

CEP: $36.036-330$ 